Proc. Indian Acad. Sci., Vol. C 2, Pt. 1, March 1979, pp. 49-66. () Printed in India.

\title{
Development of vertical axis wind turbines
}

\author{
P N SHANKAR \\ Nutional Aeronautical Laboratory, Bangalore 560017
}

MS received 9 February 1978

\begin{abstract}
This paner sunmantises the work done st the Nattonal Acronnutical Laboratory (NAL.) between 1975 and 1977 on the development of Yertical nxis wind

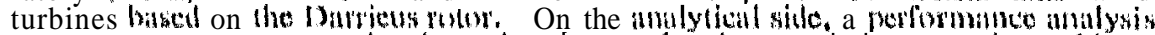
was developed which pernits the estimation of the chantatertiticy of such nuthines. A $5 \mathrm{~m}$ high wind turbine using curved wooden blades wals designcel, finbricited and iested. Both (he theory and inivisl tests contimut the low starting iorgue of the turbine. Wind tunnel tests were performed on model Silvonius rotors to determine optimum sturter hutkel configutations. Finally a stratightebladed turhine was desianed

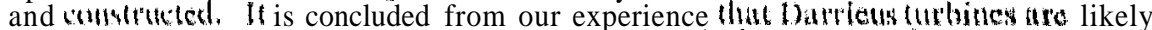

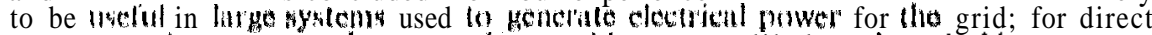
water numping junnosew, however, these turbines ure unlikely to he stuituble.
\end{abstract}

Keywords. Wind turbine; Dutrieus rotor; vertical ॥xis windmill.

\section{1, Introduction}

Verticul axis windmills have a feature that is particularly atractive -they acept wind from any horizontal direction and do not need the compliented heid mechanisms of conventional hurizontal axis windmills. The resulting ntechanical simplification is suflicient to warrant interest in any new vertical axis concept that atrises. During the early seventics, South \& Rungi $(1971,1972$ ) conducted wind tunnel tests on at novel vertical axis configurtion at the Nutions:l Restuch Council Canada, which whowed that the devieo worked efficiently at high tip speed ratios hut had poor statting torque. In elfect, the new device behaved much like a low solidity horizontal axis mathine but was conceptually a greut deal simplot. It appears that the conliguration wats originally discovered and putented by Darricus (1931). We refer to this contigurtution as tho Darricus rotor tnd when used as a turbine the vertical uxis wind turbing (VAWT').

The Darricus rulor (ligure lat) convists of a number of curved blades rolating about tho vertical axis through their ends. Sections of any blake, in Manes normal to the slope of the major (lengthwine) axis, ats of aerofoil shupe will the chords aligned in the atimuthal direction. One can understand how $\mathrm{UK}^{*}$ alevice works by studying liguros th and ls. These figures show clementul sections of a hlate ath

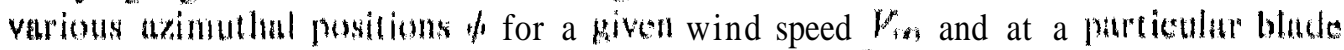
angular speed $\Omega$. When the local utimuthe spect $r \Omega$ is large compuret with tho

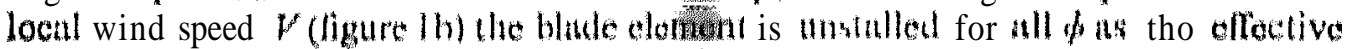
angle of atuk $a$ is small (note that $d /$ ) has been exumerated in the figure for clarity). In this condition the olemental lift $d t$, contributes pasitively to the torque while (ho 
elemental drag $d D$ detracts from it. On the other hand, when $r \Omega<V$ (figure $1 \mathrm{c}$ ), the effective angle of attack can vary from $0^{\circ}$ to $\pm 180^{\circ}$ i.e. the blade may be stalled or be in reversed flow over part of its trajectory. In this situation the elemental lift can act to reduce the torque and the elemental drag to add to it over a range of azimuthal angles. Since in the stalled case the net forces are often in opposition and since the

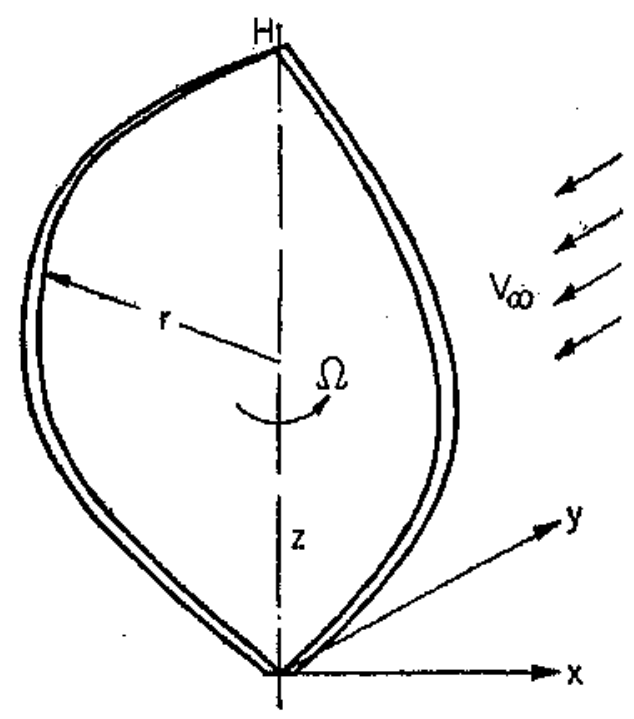

Figure la. The rotor geometry. The blades rotate about the vertical axis.

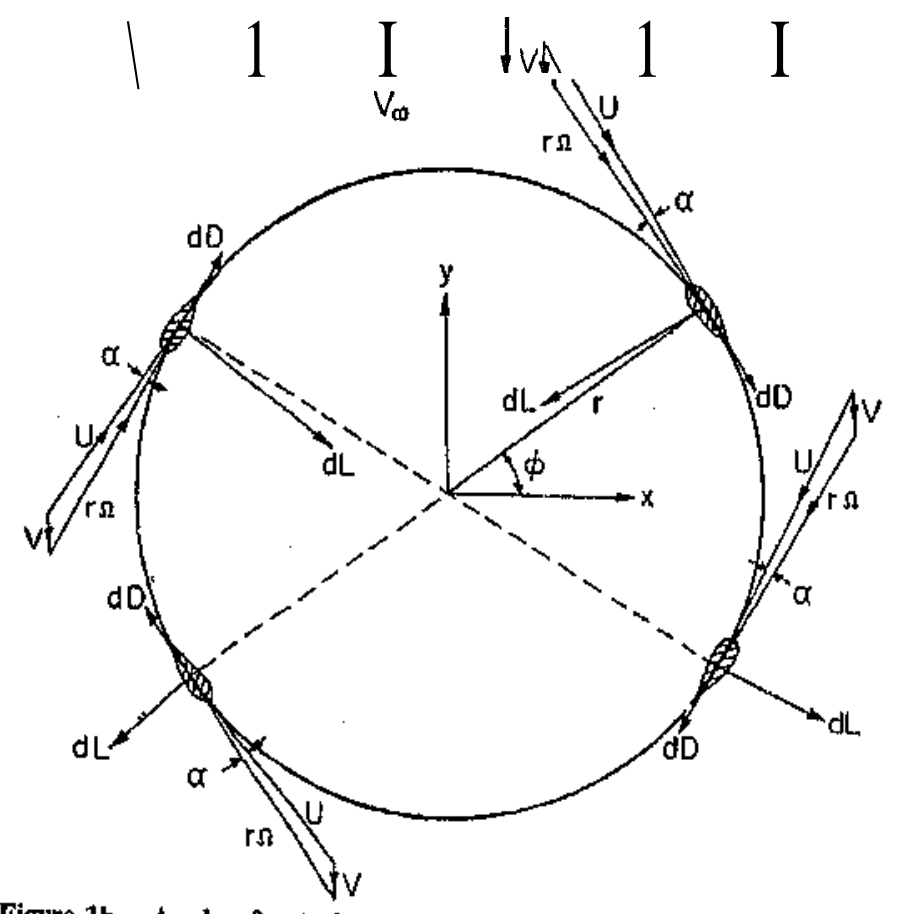

Figure 1b. Angle of attack variations about the azimuth for a blade clement whoso tip speed $r \Omega$ is large compared to the local wind speed $V$. 


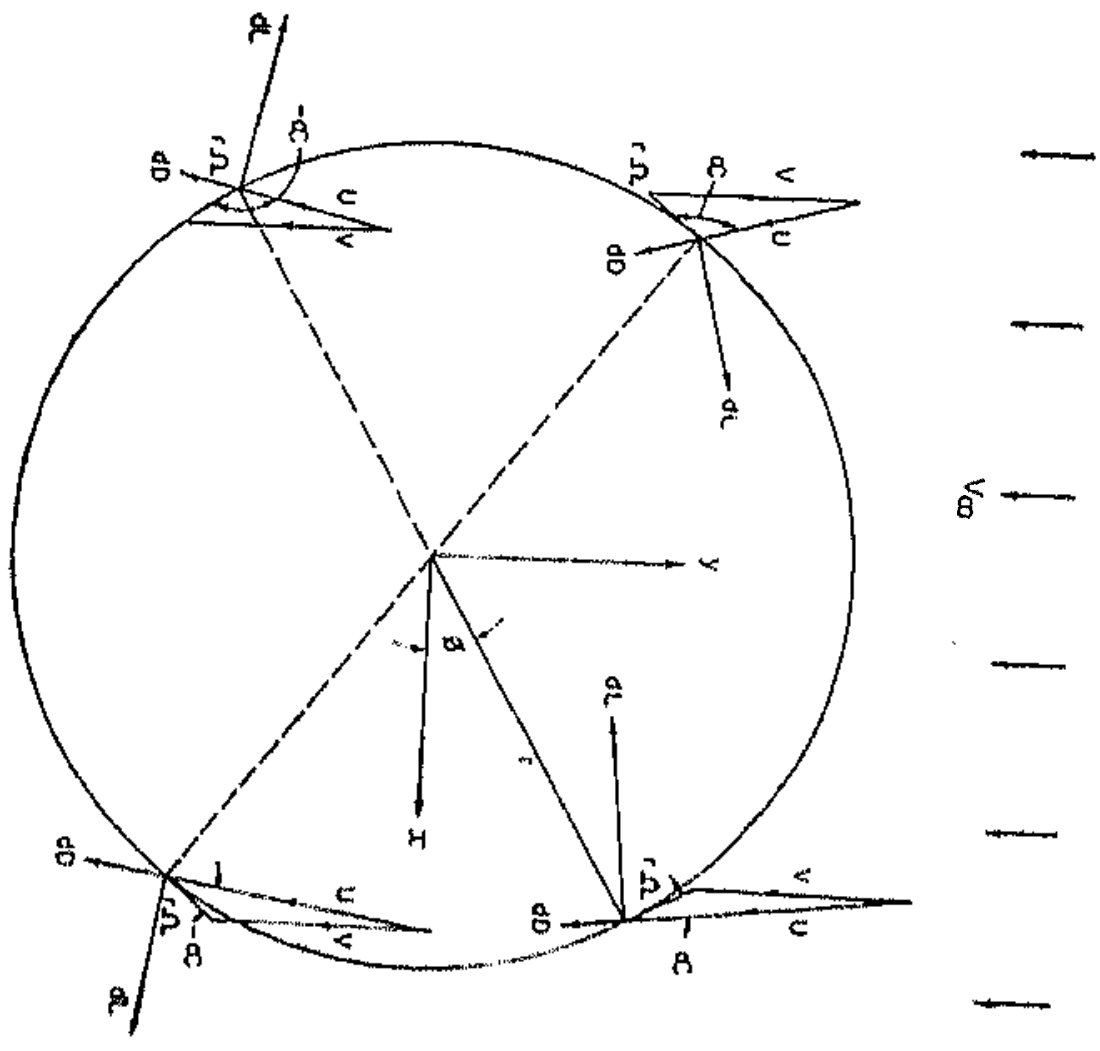

Nigure le. A pro of atuck variations for u blade clement whoso lip speed is smull
comprired to lie 10 cal wind speed. lift-tom-drang ratio i,s normally largo in the unstalled caso it follows that these machines will operate at high tip speed ratios when at peak power.

Our objective at NAL wass to loam and understand the characteristics of Darrieus rotors and to ${ }^{\mathrm{sec}}$ how feasible they would be in the Indian context, Specific goals were:

(i) to obtain a pertormance analysis for Darricus rotors,

(ii) to build a curved Waded machina,

(iii) to study the starting problem, and

(iv) to study the possibility of using struight blades.

The results of our work on these specific tusks are presented in tho following sections of (his paiper.

\section{Performunce amalysis for Darrieus rotors}

The Durrieus rotor can be analysed in un elementary wity by assuming that each soction of u blude behaves as an aerofoil in a two-dimensional flow field, dimancisnal effects are approximately accounted for by computing the ' induced velocity from momentun theory. This simple approximate method gives estimutes that compure retsonably with available experimental data, Tho uselul

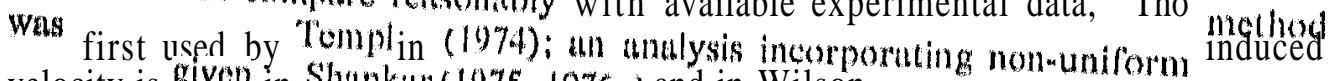
velocity is given in Shankur (1975, 1976a) and in Wilson ot al (1976). 
We first consider the induced flow. When a wind turbine operates in an air stream, the wind speed $V$ at the blades will not be equal to the true upstream wind speed $V_{\infty}$. In taking energy from the wind, the turbine exerts a decelerating thrust on the air stream. One can estimate the deceleration of the stream to a first approximation by replacing the turbine by an actuator disc (figure 2a) in the plane $y=0$. It is assumed in this approximation that the induced velocity in front and back of the rotor are equal, that it is uniform, that the flow is quasi one-dimensional with well-formed slip streams and that all losses are negligible. Under these assumptions the application of the continuity, momentum and energy equations to a large control volume leads to the result

$$
\boldsymbol{F} / \nu_{\infty}=\left(1+\frac{1}{4} C^{\prime}{ }^{\prime}\right)^{-1}
$$

where $C_{T}^{\prime}$ is the thrust coefficientbased on the local velocity $V$ :

$$
C_{T} \quad T / t_{p} .4 V^{2} \text {, }
$$

and $A$ the frontal area of the wind turbine and $\mathrm{p}$ the air density.

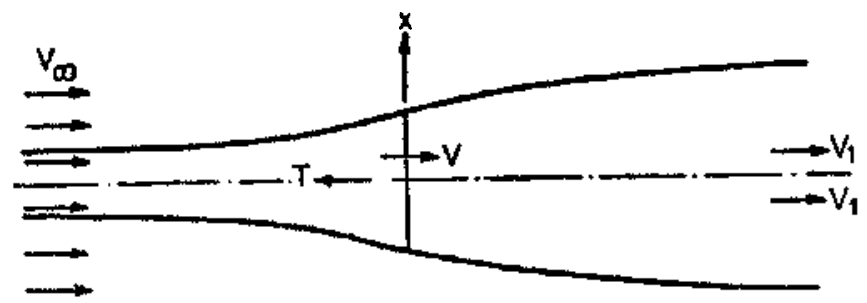

Figure 2a. Actuator disc model of the wind turbine rotor. Here $T$ is the thrust on the wind stream.

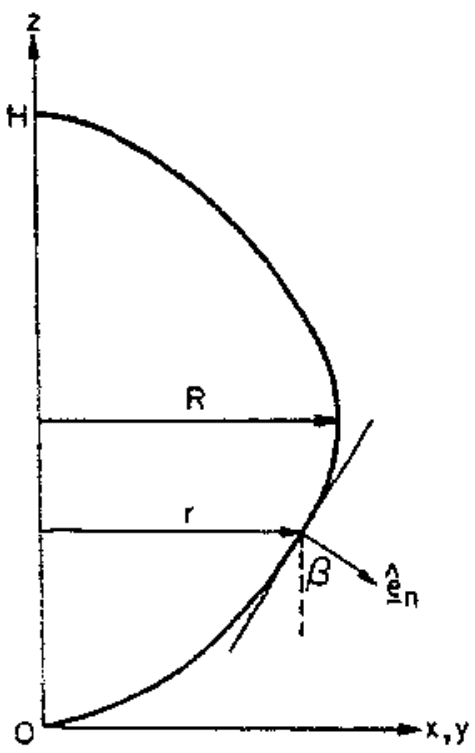

Figure 2b. View of the blade in a direction normal to the plane containing it. A is the unit vector normal to the blade chord and to the span-wise tangent to the bladee 
At a blade section distance $r$ from the axis (figure $2 b$ ) the effective wind speed $U$ contributing to lift and drag is given by

$$
V^{*}=(r \Omega \mid-V \cos \phi)^{\mathrm{a}}-\mathrm{I} \cdot(\mathrm{F} \sin \beta \sin \phi)^{2},
$$

while the effective angle of attack a at the section is determined by

$$
\tan \mathrm{a}=\mathrm{F} \sin \beta \sin \phi /\left(r \Omega+\boldsymbol{V}_{\cos } \phi\right) .
$$

If the blade is of chord $c$ with sectional lift and drag coefficients $c_{l}$ and $c_{d}$ the mean power' output $P$ and mean thrust ' $W$ for an $N$-bluded turbine are given by

$$
\begin{aligned}
& P=\frac{N}{2 \pi} \int_{0}^{I t} \int_{\mathrm{J} 0}^{2 \pi} \frac{1}{2} \rho U^{*}\left(c_{\mathrm{r}} \frac{d x d \phi}{\sin \beta},\right.
\end{aligned}
$$

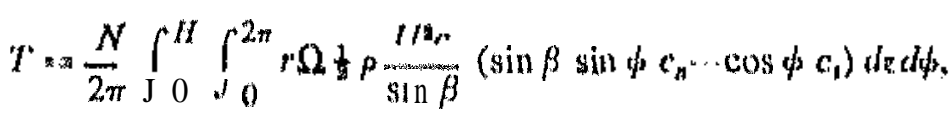

where $c$, and $c_{n}$ aro the chord-wise and normal forco coefficients given by

$$
\begin{aligned}
& a_{t} \sin a \quad c_{a} \cos a \\
& c_{n} \cdot C t \cos a \mid \cdot c_{a} \sin a .
\end{aligned}
$$

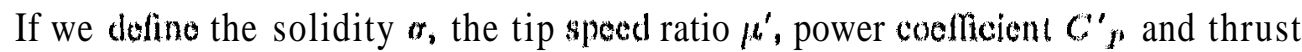
coefficient $C^{\prime}{ }_{r}$ based on the local wind speed $\psi$ as follows:

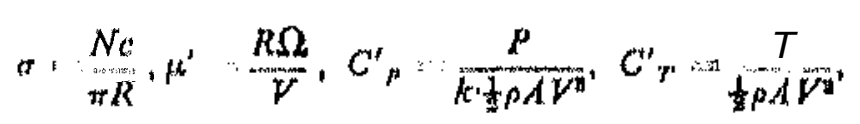

where $k-16 / 27$ and $R$ is a typical radius, and ulso normulise the rotor frontal urea and other lengths by $R$

$$
A=k_{1} R^{H}, \vec{r}: \ldots / R_{v}:: R / R,
$$

equations (5a), (5b), (3) and (4) may be rewritlen

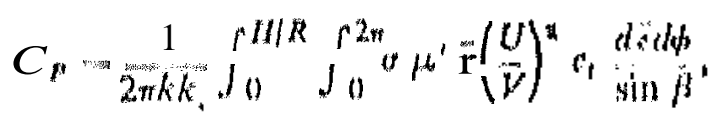

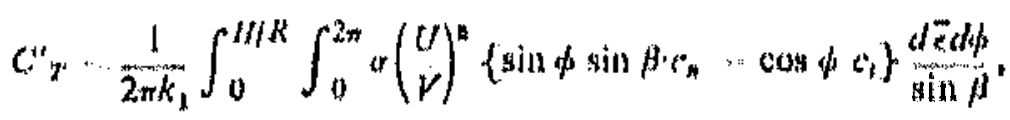

$$
\begin{aligned}
& (U / V)^{n}-\left(r \mu^{n}+\cos \phi\right)^{\sharp}+(\sin \phi \sin f t)^{*}, \\
& \left.\tan a . \sin f t \sin \phi /\left(r^{\prime} \mu^{\prime}+\right)^{-} \cos \phi\right) \text {. }
\end{aligned}
$$

$F,(C)-1$ 
In practice se require the tip speed ratio $\mu$, power coefficient $C_{P}$ and thrust coefficient $C_{F}$ based on the true wind speed $V_{\sigma o}$. By using (1) for the induced velocity we obtain

$$
\begin{aligned}
& f \sim \mu^{\prime} V_{\alpha}=\mu^{2}\left(1+\frac{1}{2} C_{\tau}^{*}\right)^{-1} \text {, } \\
& C_{T}=C_{T}^{\prime}\left(V^{\prime} V_{x}\right)^{2}=C_{T}^{\prime}\left(1+\mathrm{i} C_{T}^{\prime}\right)^{-2} \text {, } \\
& C_{P}=C_{P}\left(V V_{S}\right)^{3}=C_{P}^{\prime}\left(1+\frac{1}{4} C_{T}\right)^{-3} \text {. }
\end{aligned}
$$

The calculational procedure is then as follows. With the blade and rotor geometry given $C_{P}^{\prime}$ and $C_{T}$ are computedas functions of $\mu^{\prime}$ by evaluating the integrals (9a) and $(9 b)$. Once these have been computed the true tip speed ratio $\mu$, power coefficient $C_{P}$ and thrust coefficient $C_{T}$ may be calculated using (1Oa), (10b) and (1Oc). A useful linearisation for high tip speed ratios and a method of incorporating nonuniform induced velocity are given in Shankar (1976a). In figures 3a and 3b computations based on the performance analysis are compared with the experimental results of South \& Rangi (1972). It may be seen that the agreement is generally satisfactory. Thus, the analysis is a useful tool for the design of Darrieus rotors.

\section{Curved Haded turbime}

in order to gain direct experience in the design, construction and operation of VAWTs it was decided ia 1975 that a turbine be built at NAL. At the outset it was decided that simplicity, aveilability of materials and speed of fabrication would be the most importanst. considerations. The design did not therefore take into consideration the problems that might arise in mass production; nor was economics considered except in so far as to avoid unnecessary or wasteful expenditure.

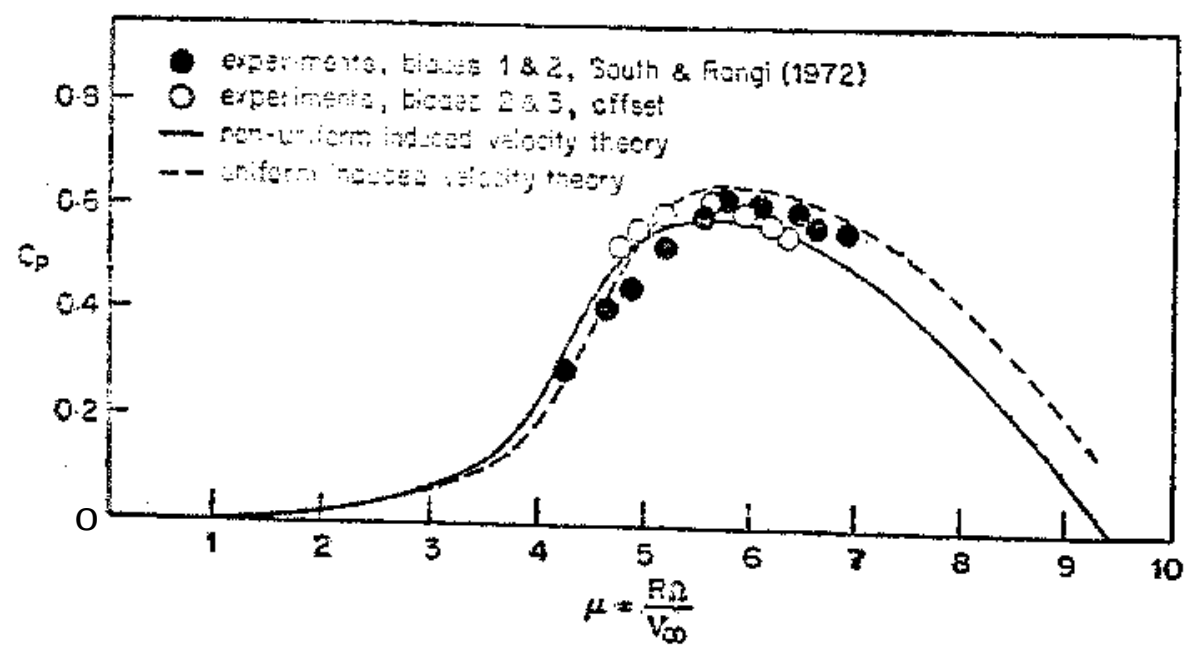

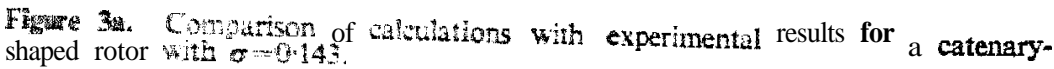




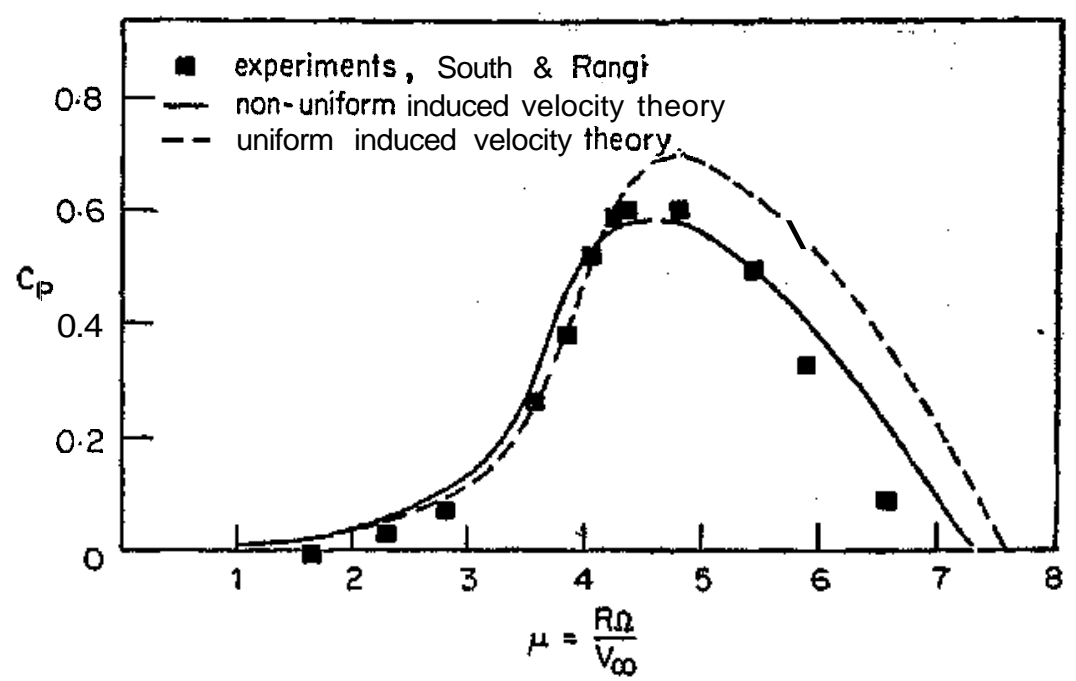

Figure 3b. Comparison of calculations with experimental results for a parabolic rotor with $\boldsymbol{\sigma}=0.25$.

Aerodynamic performance calculations led to the following specifications (Shankar 1975).

$\begin{array}{ll}\text { Power output } & 1000 \mathrm{~W} \text { in winds of about } 25 \mathrm{~km} / \mathrm{hr} \\ \text { Rev/min } & 135 \text { at rated power and wind speed } \\ \text { Frontal area } & 17 \cdot 2 \mathrm{~m}^{2} \\ \text { Blade shape } & \text { Catenary of diameter } 5 \mathrm{~m} \text { and height } 5 \mathrm{~m} \\ \text { Number of blades } & 2 \\ \text { Aerofoil section } & \text { NACA } 0012 \text { of chord } 250 \mathrm{~mm} \\ \text { Starters } & \text { Two Savonius buckets of height } 1 \mathrm{~m} \text { and diameter } 2 \mathrm{~m} .\end{array}$

Figure 4 shows a sketch of the turbine configuration and support system. The central column is a welded structure made of three $25 \mathrm{~mm} \times 25 \mathrm{~mm} \times 6 \mathrm{~mm}$ angles located at the vertices of an equilateral triangle of base $250 \mathrm{~mm}$. The rotor is supported on a four-legged steel table with the table top $2 \mathrm{~m}$ above the ground. The central column rotates with the blades, the upper bearing being held in place by three $6 \mathrm{~mm}$ guy wires. A simple band brake assembly was used for emergency breaking, the assembly being located below the lower bearing.

The method of construction of the blades was as follows. Two steel tubes, approximately $13 \mathrm{~mm}$ in diameter were bent to the shape of the catenary. A wooden former also of the same shape was erected so that the blades could be built on the former. Now wooden pieces, approximately $25 \mathrm{~mm}$ thick, were roughly shaped to the aerofoil profile. These pieces had two slots, $13 \mathrm{~mm}$ wide, cut out equidistant from the quarter chord point and spaced $52 \mathrm{~mm}$ apart. The wooden pieces were assembled on the former, the steel tubes placed in the slots, and the wooden pieces glued together. The outer surfaces were then finished to the aerofoil profile. The blades were then finally finished with fibreglass cloth (for weather protection and extra strength), smoothed with putty and painted. 


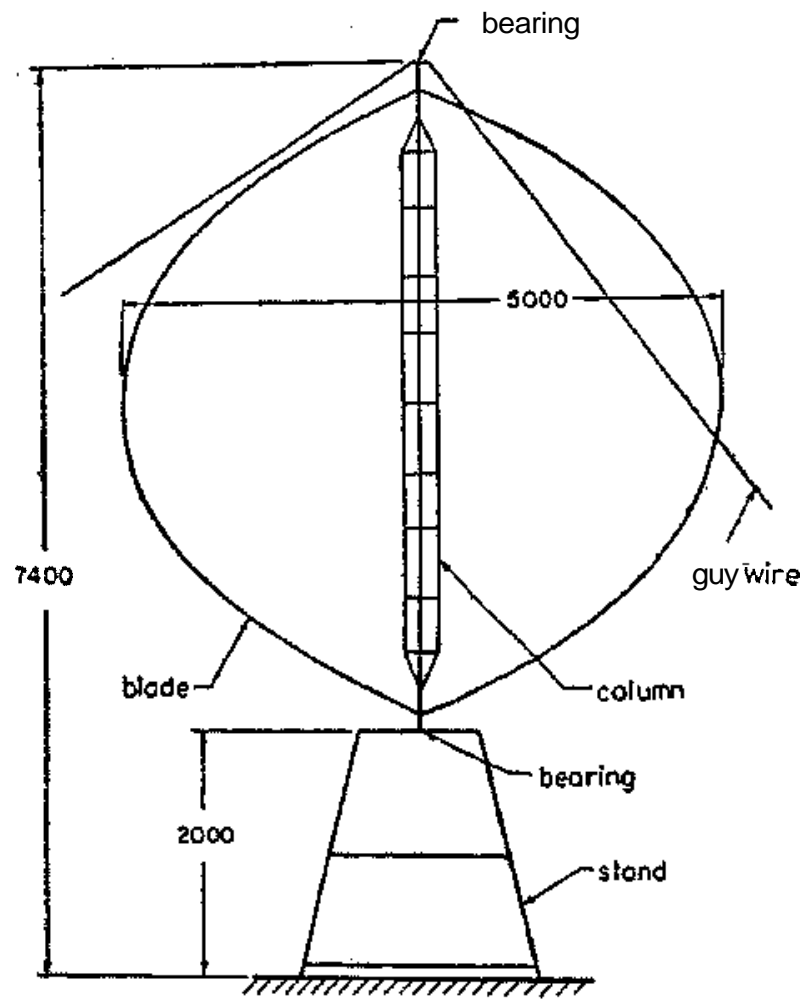

oll dimensions in $\mathrm{mm}$

Figure 4. Sketch of the wind turbine configuration and support system.

The turbine was used to drive a commercially available self-priming centrifugal pump rated at 1 h.p. at a shaft speed of $1440 \mathrm{rev} / \mathrm{min}$. A 9.3:1 step-up gear box using chain and sprockets was used for shaft speed matching. The choice of the load was poor as the commercial pump requires high starting torque and is very inefficient, In fact a separate d.c. motor was used for on-load starting purposes.

Figure 5 (plate 1) shows a photograph of the VAWT. Details of the findings of the initial tests are given in Shankar (1975). In summary it was found that:

(i) the turbine did generate $1 \mathrm{~kW}$ and more in winds of $25 \mathrm{~km} / \mathrm{hr}$ and above;

(ii) the turbine was not self-starting on load. With the $2 \mathrm{~m}$ diameter Savonius buckets, self-starting on no load occurred in winds of about $10 \mathrm{~km} / \mathrm{hr}$;

(Hi) the turbine-bearing system, which consisted of a 7211 angular contact bearing (55 $\mathrm{mm}$ i.d.) at the bottom and a 1205 self-aligning bearing $(25 \mathrm{~mm}$ i.d.) at the top, had a high starting frictional torque of the order of $1.5 \mathrm{~kg} . \mathrm{m}$. The estimated total vertical load in this configuration was between 300 and $400 \mathrm{~kg}$; (iv) the conventional centrifugal pump is not suitable for this type of turbine.

Following the initial tests various modifications were considered and implemented. A configuration having the central column stationarywas tried out (figure 6, plate2). A clutch assembly was designed and fabricated which permitted the rotor blades to be off-load at start and to engage the load only when the rotor rev/min was around 70 . The device used the centrifugal load of the blades to lift a friction pad concentric to 
the shaft; initially the pad was free but at around $70 \mathrm{rev} / \mathrm{min}$ its vertical movement forced it to engage the load. This configuration was found to be superior to the initial one used as far as starting characteristics are concerned.

\section{Wind tunnel tests of Savonius rotors}

The Savonius rotor is a vertical axis device which has a high starting torque and reasonable peak power output. Its use as a windmill has been restricted till now because of the large surface area it employs. However, there has been renewed interest in this device in view of its simplicity. Using cloth-like surfaces it now appears that Savonius windmills may have potential in regions of low mean wind speed for generating small amounts of power for water pumping etc. (see Govindaraju \& Narasimha 1977, 1979). At NAL, interest in the Savonius rotor stemmed fromits use ${ }^{\text {as }}$ a starter for the Darrieus rotor. In view of the negligible amount of reliable data on Savonius rotors it was decided to test a range of configurations in the Boundary Layer Tunnel at NAL.

Both two-bladed and three-bladed geometries were tested. Figures $7 \mathrm{a}$ and $7 \mathrm{~b}$ show the configurations that were tested. The models, made of $1 \mathrm{~mm}$ aluminium sheets, were of diameter $200 \mathrm{~mm}$ and height $70 \mathrm{~mm}$. The models were tested in the open jet of a wind tunnel of rectangular section of dimensions $1.51 \mathrm{~m} \times 0.305 \mathrm{~m}$. Thus the blockage of $3 \%$ was quite small. Tests were carried out at wind speeds ranging from $7 \cdot 6 \mathrm{~m} / \mathrm{s}$ to $15 \cdot 2 \mathrm{~m} / \mathrm{s}$ and model rev/min ranged from 0 to 2300 .

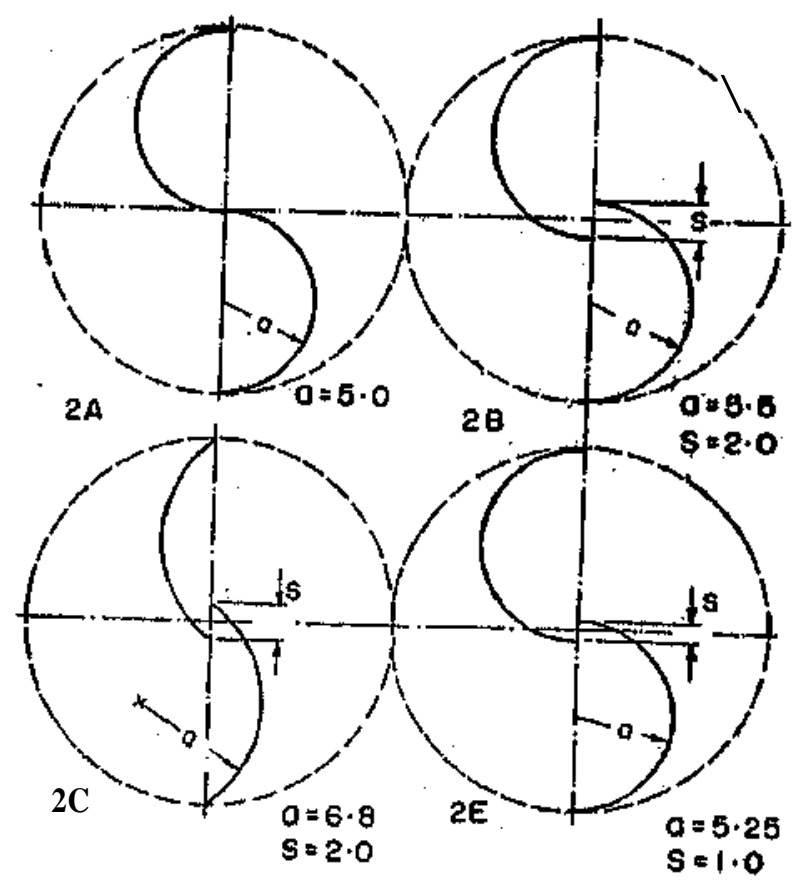

Figure $7 \mathrm{a}$. The geometrical characteristics of two-bladed Savonius rotor models;
$d=20 \mathrm{~cm}$. 


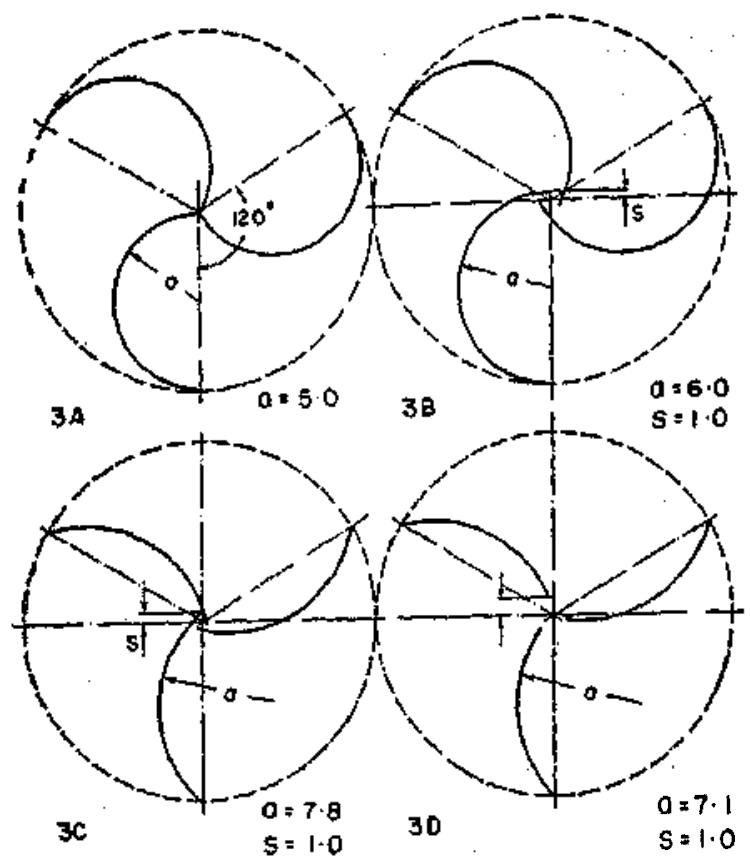

Figure $\mathbf{7 b}$. Geometrical characteristics of three-bladed Savonius rotor models; $d=20 \mathrm{~cm}$.

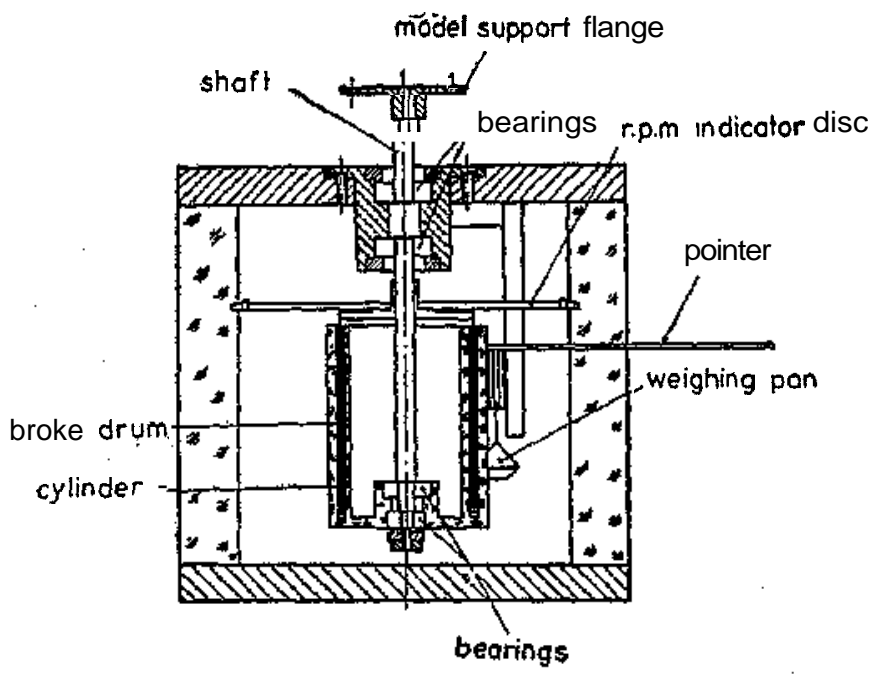

Figure 8. Sketch of the viscous dynamometer used in the wind tunnel experiments,

The balance used was a viscous dynamometer and is sketched in figure 8. Details of the dynamometer are given in Shankar (1976b).

Figures $9 \mathrm{a}$ and $9 \mathrm{~b}$ show the measured variation of power coefficient $C_{P}$ with tip speed ratio $\mu$ for the two-bladed and three-bladed models. It is clear that the twobladed rotors generally have much higher peak power output than the three-bladed rotors. The significant findings of the tests were 


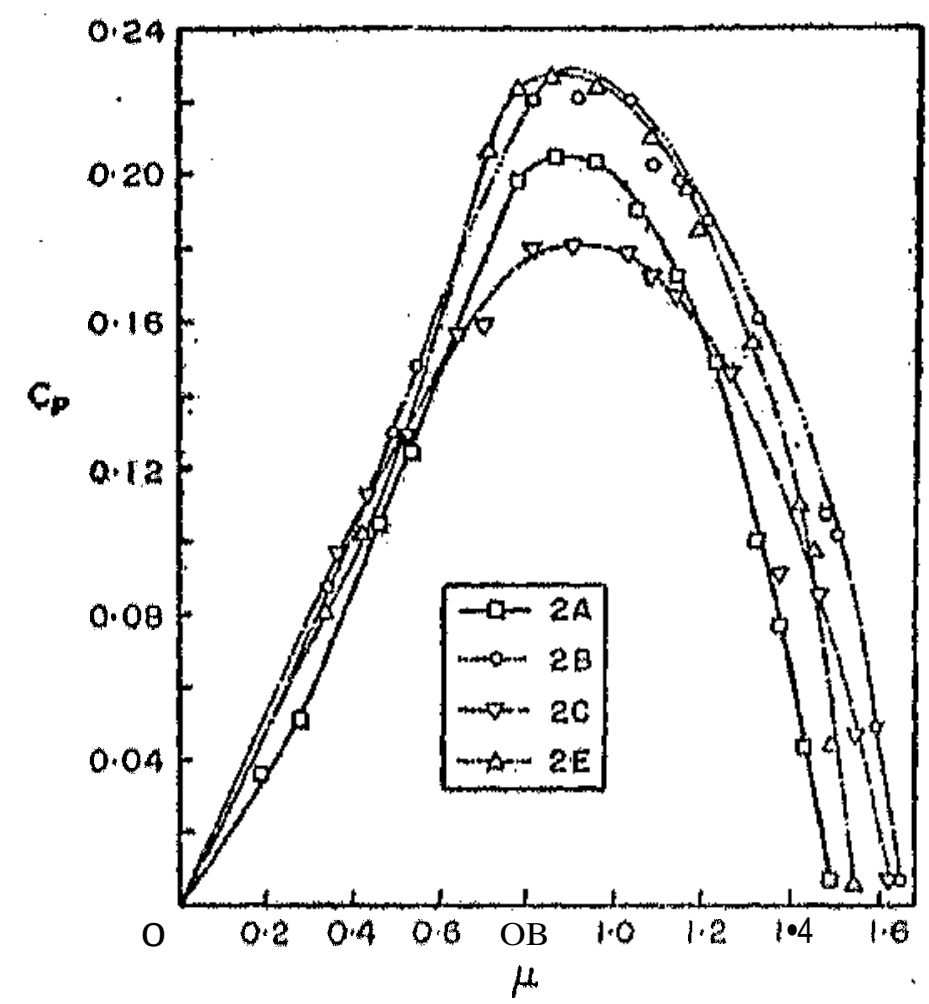

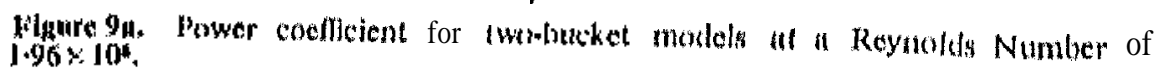

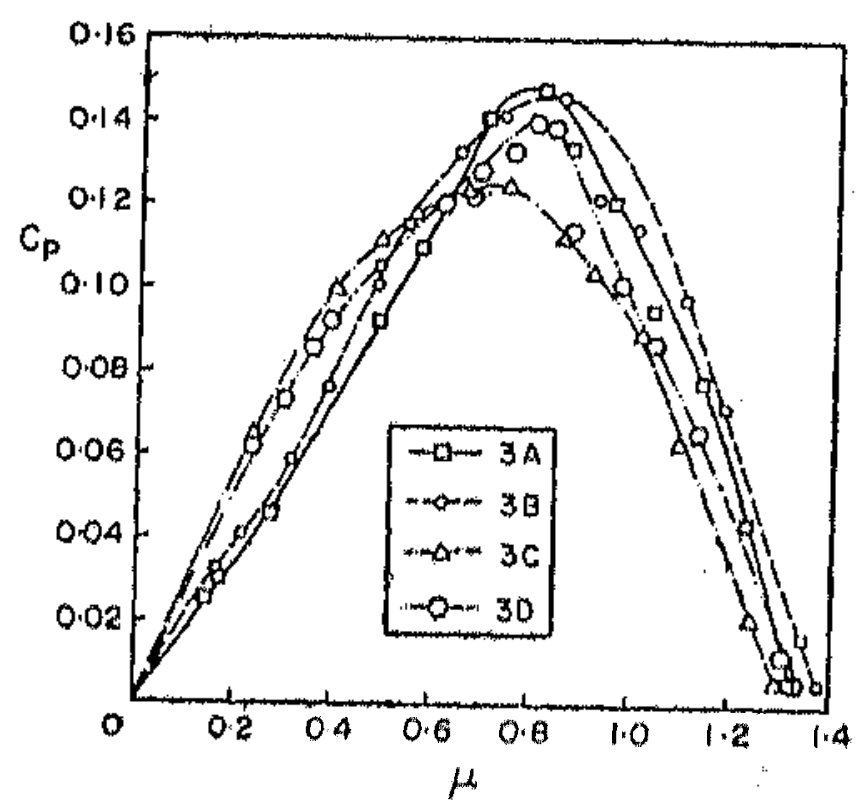

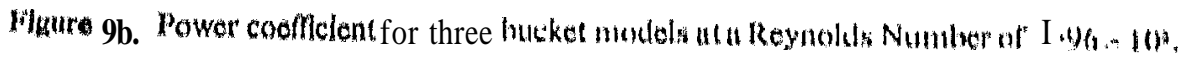
(i) in the runge of Reynolds Numbers tested, the porlormune of inll Suvonius lype otors improved with Roynolds Number: 
(ii) two-bladed Savonius rotors have almost $50 \%$ higher peak power output than the three-bladed rotors;

(m) three-bladed rotors have smaller regions of negative starting torque but the torque coefficient at start is not significantly larger than that for two-bladed models;

(iv) while gap size is of some significance for the two-bladed models it is not of much significance for three-bladed models;

(v) shallow bucketed models have higher torque at low tip speed ratios but have worse peak performance;

(vi) a support rod at the centre of a Savonius rotor with a gap does not significantly affect its performance.

Most of the above findings have been confirmed in tests done at the Sandia Laboratories by Blackwell et al (1977).

\section{The straight Waded turbine}

A great disadvantage of the Darrieus rotor is the complication inherent in the fabrication of the curved blades. The large curved blades also pose a problem in handling, transportation and assembly. The main reasons for using curved blades are structural. The curved blade minimises bending stresses and the attachments to the top and bottom of the central shaft help to minimise vibrations. However, the possibility of using straight blades has remained an intriguing one over the years.

At NAL, a decision was made to try out a turbine using straight blades. At the outset it was decided that, in order to limit bending stresses and centrifugal loads, the upper rev/min would be strictly limited. The blades too would be of minimum weight.

Figures $10 \mathrm{a}$ (plate 3 ) and $10 \mathrm{~b}$ (plate 4) show photographs of two- and three-bladed versions of the straight-bladed turbine. The blades were fabricated out of aircraft quality aluminium sheets with internal stiffeners. The specifications of the turbine were as follows.

Power output $1 \mathrm{~kW}$ in winds of speed $25 \mathrm{~km} / \mathrm{hr}$

Shaft speed $80 \mathrm{rev} / \mathrm{min}$ for the two-bladed and $70 \mathrm{rev} / \mathrm{min}$ for the threebladed version at rated power and wind speed

Frontal area $17 \mathrm{~m}^{\mathrm{3}}$

Blade length $\quad 2.44 \mathrm{~m}$

Blade profile Conforming to NACA 0024 section of chord $0.44 \mathrm{~m}$

Starters 2 Savonius rotors of height $1 \mathrm{~m}$ and diameter $2 \mathrm{~m}$

The $24 \%$ thick section and the large chord were used to minimise bending stresses in the sheet metal.

While the turbine pick-up, starting friction and general performance were found to be satisfactory it was found that the support system was inadequate especially at revolutions greater than $100 \mathrm{rev} / \mathrm{min}$. It has been our experience both with the straight-bladed turbine and the curved-bladed one that guy wire supports are really not adequate. In any practical system the upper bearing must be housed in a rigid structure. 


\section{Conclusions}

The development work done at NAL gave us experience in the design, fabrication and field testing of Darricus turbines. There is no doubt that the Darricus rotor is a high speed device of efficiency comparable to horizontal axis windmills. It seems likely that this device will find use in the conversion of wind energy to electric power especially if used on a large scale in conjunction with the grid. In fact a $200 \mathrm{~kW}$ turbino driving a generator is at present being tested in Canada. With such large devices it is quite feasible to have adequate control systems for starting and controlling the systom. In India, however, the mean wind speeds are genorally so low that it is unlikely that wind power can be economically convorted to electric power for grid atugmentution. The most practical use for wind power is likely to bo direct water pumping for drinking water and minor irrigation purposes. The water pumping application generally implies high starting torque and low control costs. Illonce it appears, at least from the NAL experience, that Darricus turbines arc not likely to be of much use in tho Indian context.

\section{References}

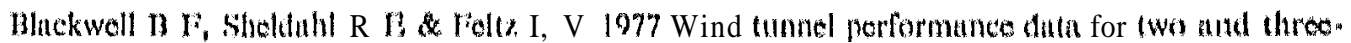
hucket Savonitus rotors, Stmilia linb. Rep. SAND 76;0131

Darrieus (i.I M 1931 US Patent No, I 815 OIK

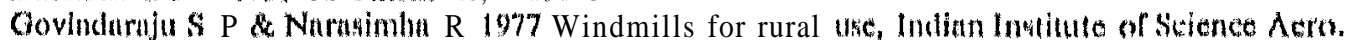
Report 77 I'M 14

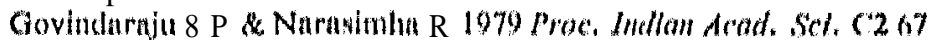

Shunkur $P$ N 1975 'The design, fabriention and preliminary testing of NAl's $1 \mathrm{~kW}$ vertical axis wind turbine, NAL Memorandum Ar:-1"M-22.75

Shankar P N 1976a Proce. $R$, Soe. (temton) A349 35; also 1975 NAI. Memorandum Al:-1M.11.75

Shankar P N 1976h The eflets of geometry and Reynolds Number on Stwonius type rotur: NAL Memorandum A1:-TM-7\% 76

South P \& Rangi RS 1971 prollminary tests of a high spred vertical axis windmill model, NRC: Report L.TR-I.A-74

South P A Rangi R S 1972 A wind tunnol investigntion of a $14 \mathrm{ft}$ diameter vertical ukis windmill, NRC: Report 1.TR=L ${ }_{n} \Lambda=105$

Tomplin R J 1974 Aerotymamie performanco theory for the NRC vertical axis wind lurbine,

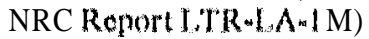

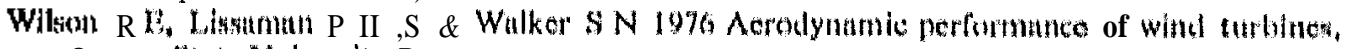
Oregon Stute University Report 
Plate 1

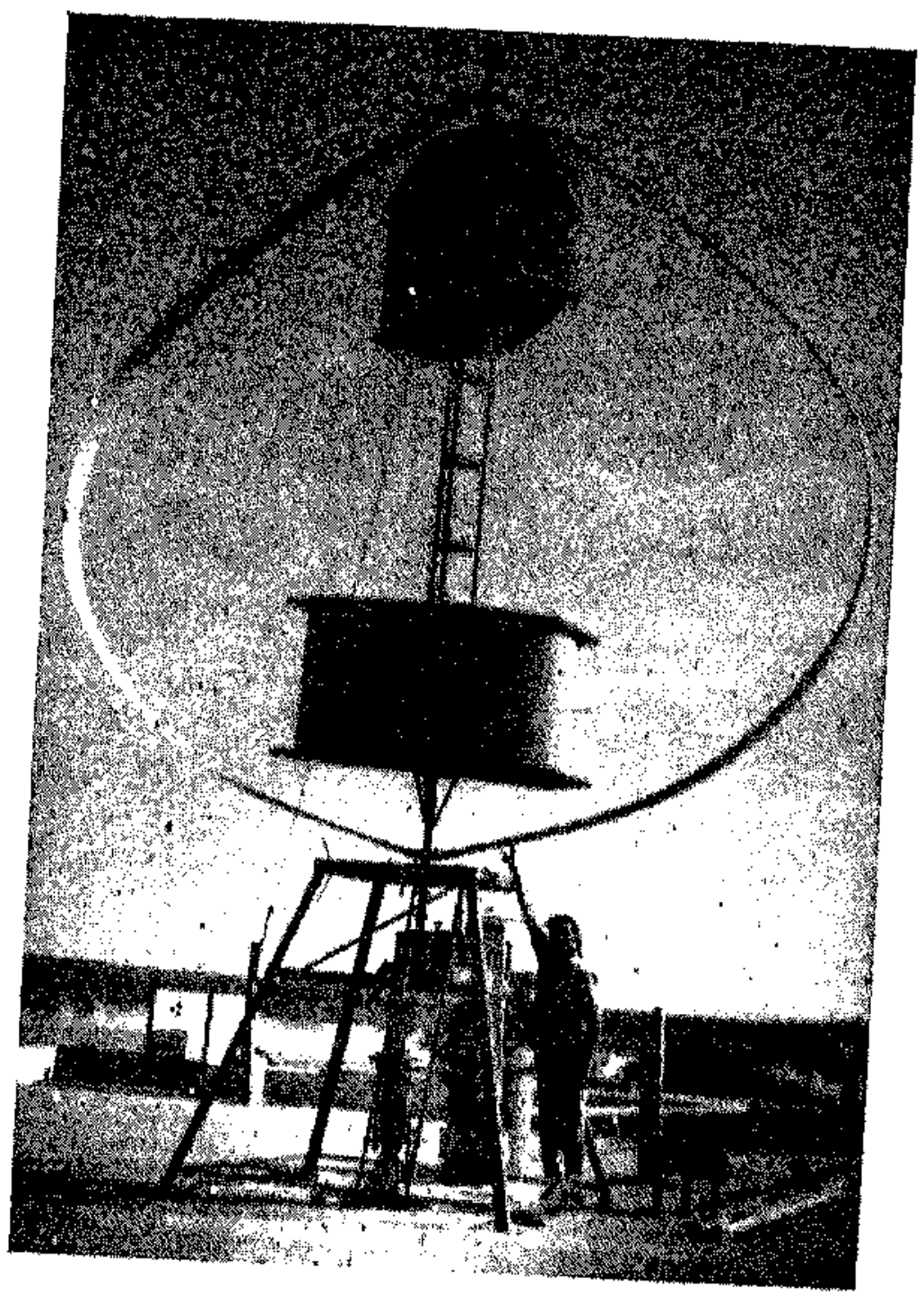

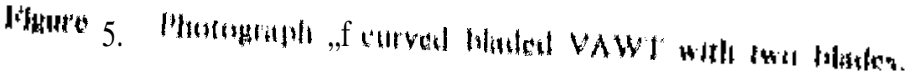




$$
4
$$


Plato 3

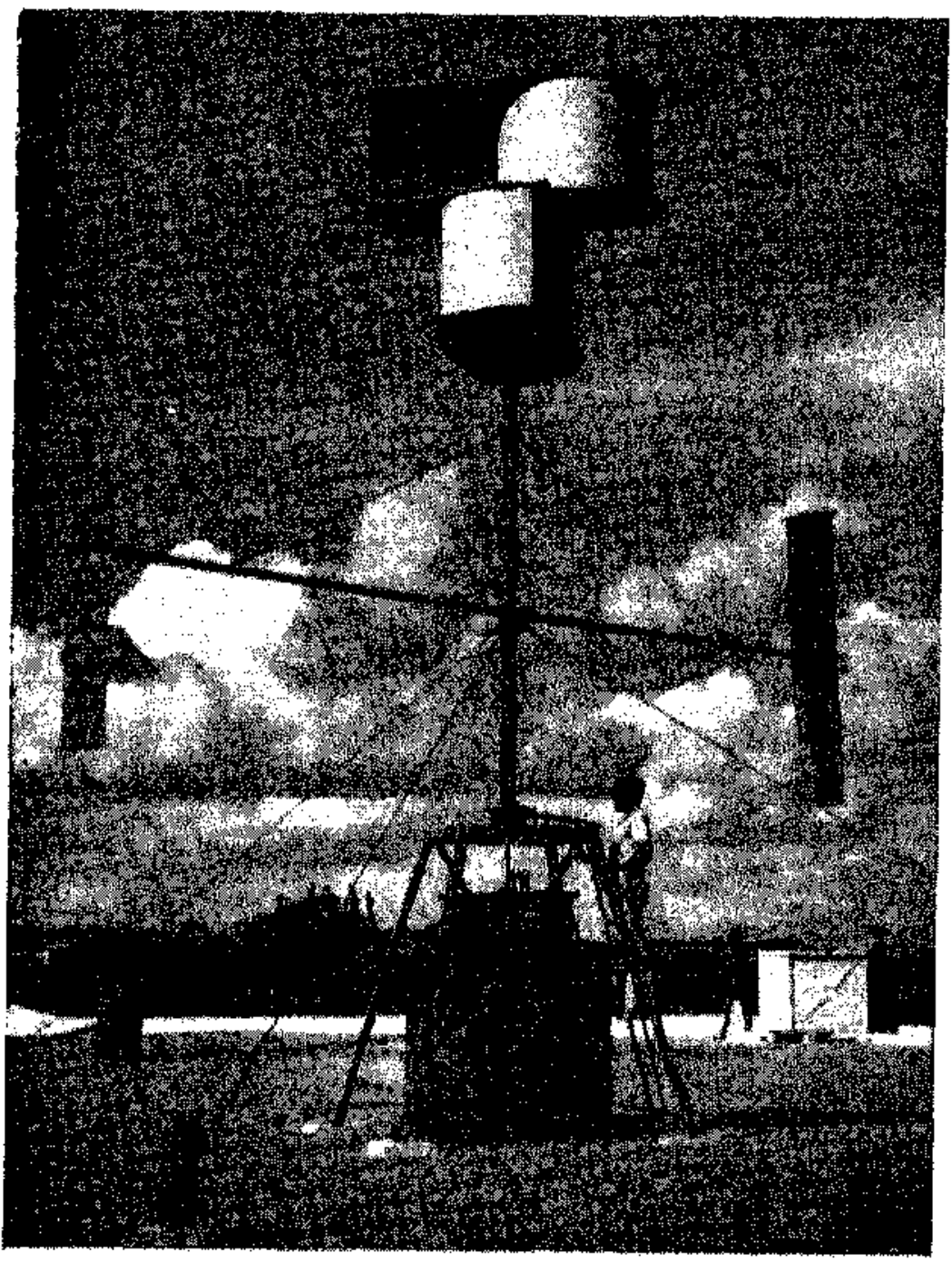

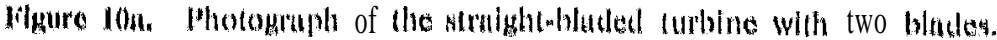


Plate 4

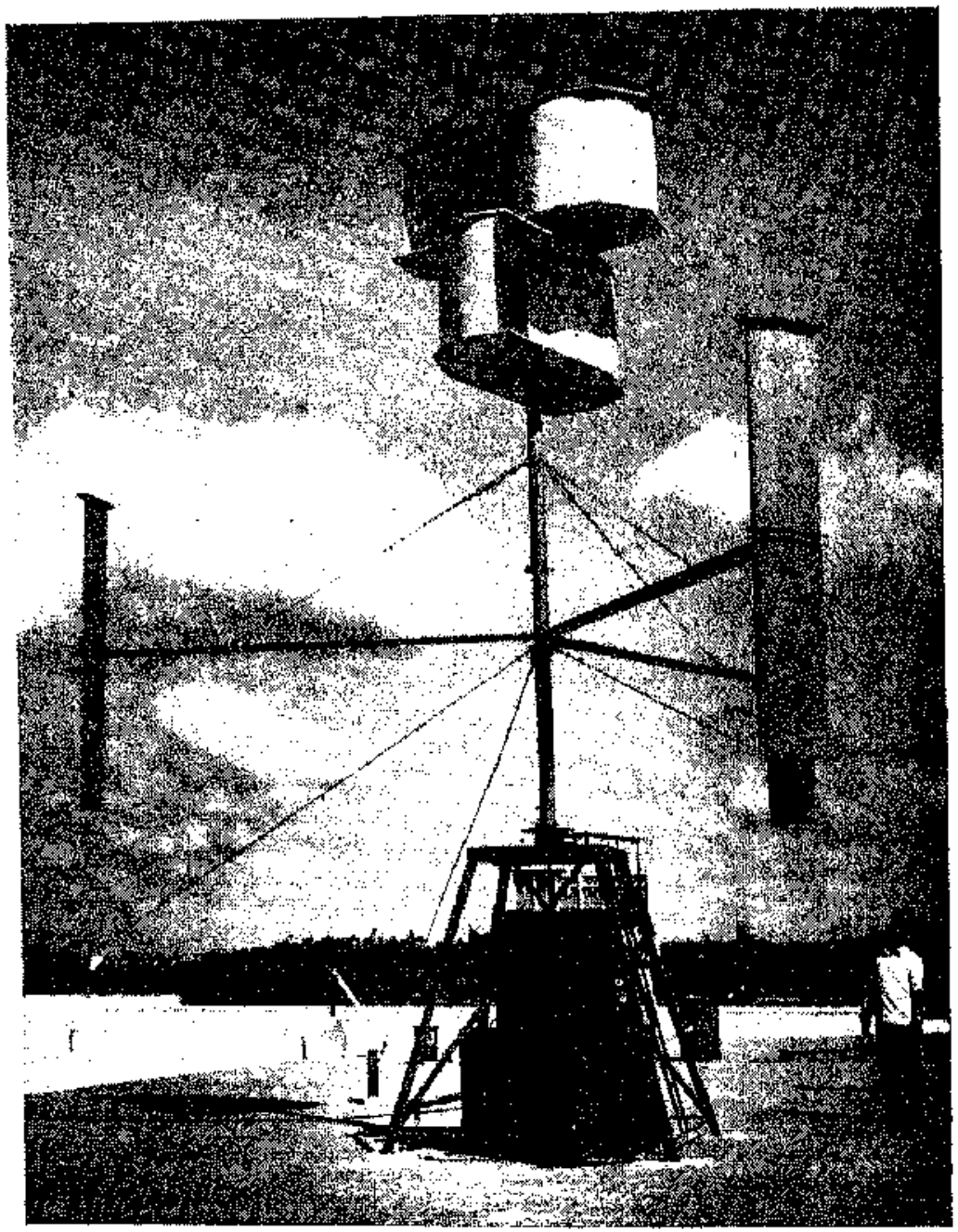

Figure 10b. Photograph of the straight-bladed turbine with 3 blades. 